\title{
Investigational Product Handling Instruction
}

National Cancer Institute

\section{Source}

National Cancer Institute. Investigational Product Handling Instruction. NCI Thesaurus.

Code C115525.

Documentation that describes the safe handling, storage, distribution, and return of unused investigational product (IP) during the entire study period, including transit to and from the sponsor's facility. 